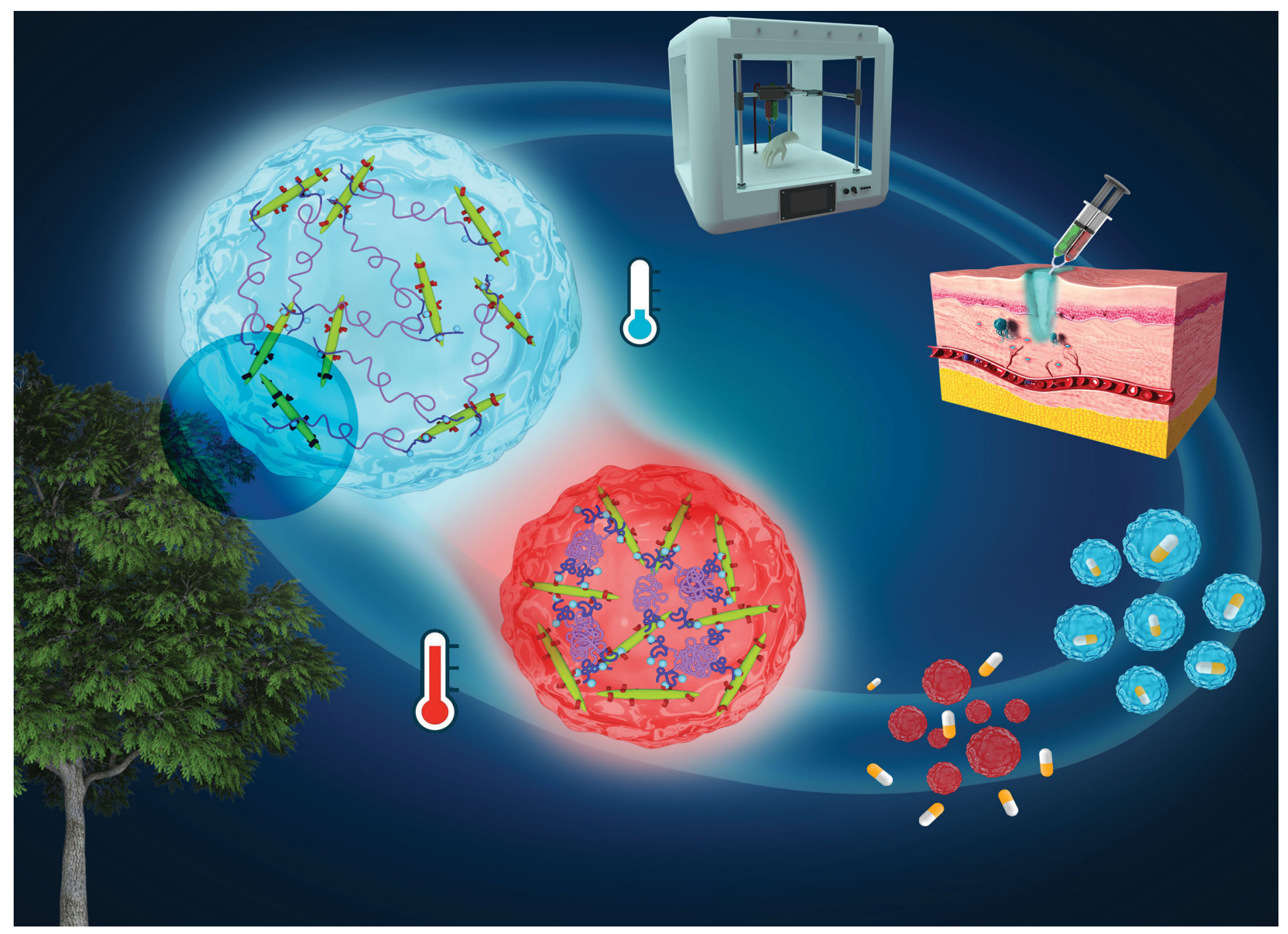

Showcasing research from Professor Kam C. Tam's laboratory, Department of Chemical Engineering, University of Waterloo, Ontario, Canada.

Stimuli-responsive hydrogel consisting of hydrazide-functionalized poly(oligo(ethylene glycol)methacrylate) and dialdehyde cellulose nanocrystals

Polymeric hydrogels have attracted increasing attention in several potential applications, such as tissue engineering and drug delivery systems. Stimuli-responsive hydrogels are increasingly being used in medicine due to their sol-gel transition and reversible swelling-shrinking behavior in response to external stimuli. Herein, a hydrogel consisting of hydrazide-functionalized poly(oligo(ethylene glycol)methacrylate) and dialdehyde cellulose nanocrystals (extracted from wood pulp) was developed and its thermo-responsive and self-healing properties critical to several biomedical applications, i.e. tissue engineering, wound dressing, and controlled drug delivery are demonstrated.

\section{As featured in:}

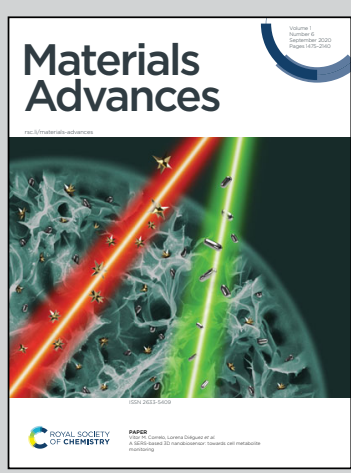

See Rasool Nasseri and Kam C. Tam, Mater. Adv., 2020, 1, 1631. 
Check for updates

Cite this: Mater. Adv., 2020, 1,1631

\title{
Stimuli-responsive hydrogel consisting of hydrazide-functionalized poly(oligolethylene glycol)methacrylate) and dialdehyde cellulose nanocrystals $\uparrow$
}

\author{
Rasool Nasseri ${ }^{\mathrm{ab}}$ and Kam C. Tam (D) *ab \\ A self-healable thermo-responsive hydrogel was produced via the formation of acylhydrazone bond \\ between dialdehyde-functionalized cellulose nanocrystals (DACNC) and hydrazide-functionalized \\ poly(oligo(ethylene glycol) methacrylate) (POEGMA-H). POEGMA-H displayed a two-step phase \\ transition upon increasing the temperature due to the coil to globule transition of the middle and end \\ segments of the polymer chains. Rheological measurements revealed a significant increase in hydrogel \\ stiffness (from $11 \mathrm{~Pa}$ to $1907 \mathrm{~Pa}$ ) due to the coil to globule transition of POEGMA-H chains when the \\ temperature was increased from 25 to $75{ }^{\circ} \mathrm{C}$. With increasing concentration of DACNC, the stiffness of \\ the hydrogel was enhanced. At low and medium pHs, stable hydrogels were formed, however, at high \\ $\mathrm{pH}$, gradual formation of acylhydrazone bonds led to a loose network. The hydrogel possessed self- \\ healing capability with close to $100 \%$ recovery in the storage modulus at medium $\mathrm{pH}$, and it has great \\ potential in biomedical applications.
}

Received 9th June 2020,
Accepted 3rd August 2020
DOI: $10.1039 /$ dOma00397b
rsc.li/materials-advances

\section{Introduction}

Polymeric hydrogels with high water content and three-dimensional structure mimic natural matrices. They have attracted increasing attention in several applications, such as tissue engineering, ${ }^{1}$ delivery vehicles ${ }^{2-4}$ etc. Stimuli-responsive hydrogels are increasingly being used in the biomedical science due to their sol-gel transition and reversible swelling-shrinking behavior in response to stimuli, such as $\mathrm{pH}$, temperature, light, and magnetic fields. ${ }^{5-9}$ In situ gelling or injectable hydrogels are of particular interest, because their delivery modality is via minimally invasive injection, contrary to pre-formed hydrogels that must be surgically implanted. ${ }^{10,11}$ The crosslinking mechanism plays an important role in the final properties of the hydrogels. Self-healing or the ability of self-repair is one of the properties that can be produced in a hydrogel with a rational crosslinking strategy. Two major crosslinking approaches can be employed to prepare self-healing hydrogel, namely dynamic noncovalent interactions (host-guest interactions, ${ }^{12}$ metal ion co-ordinations, ${ }^{13,14}$ electrostatic interactions ${ }^{15,16}$ ) and reversible covalent bonds

\footnotetext{
${ }^{a}$ Department of Chemical Engineering, University of Waterloo, 200 University Avenue West, Waterloo, Ontario, N2L 3G1, Canada. E-mail: mkctam@uwaterloo.ca; Tel: +1 (519)888-4567 ext38339

${ }^{b}$ Waterloo Institute for Nanotechnology, University of Waterloo, 200 University Avenue West, Waterloo, Ontario, N2L 3G1, Canada † Electronic supplementary information (ESI) available. See DOI: 10.1039/ d0ma00397b
}

(boroneoxygen bonds, ${ }^{17}$ sulfur-sulfur bonds (disulfide), ${ }^{18}$ carbonnitrogen bonds (imine, ${ }^{19}$ enamine,${ }^{20}$ and acylhydrazone ${ }^{21-23}$ ), cyclohexenes (reversible Diels-Alder cycloaddition ${ }^{24}$ )). Some of the reversible covalent bonds, such as acylhydrazone and disulfide are degradable in physiological environment, making them particularly advantageous in biomedical applications. ${ }^{25}$ Conflicting needs for both high stiffness (necessary for practical application) and high molecular dynamics (a requirement for the healing process), are some of the challenges in designing self-healable hydrogels. To address this, cellulose nanocrystals (CNCs) can be employed in self-healable hydrogels due to their desirable mechanical characteristics, such as high surface area $\left(\sim 250 \mathrm{~m}^{2} \mathrm{~g}^{-1}\right)$, high tensile strength $(7500 \mathrm{MPa})$, and high stiffness (Young's modulus up to $140 \mathrm{GPa}$ ). ${ }^{26}$ Additionally, the abundance of reactive surface hydroxyl groups on the surface of $\mathrm{CNC}$, provides a platform for functionalization and integration to form self-healable hydrogels. ${ }^{27}$ By adding CNC, the stiffness of the hydrogel can be enhanced with minimal disruption of the molecular dynamics. ${ }^{28}$

Poly(oligo(ethylene glycol) methacrylate) (POEGMA) based hydrogels have gained increasing attention in biomedical applications, owing to their high tissue compatibility, facile functionalization and thermo-responsive properties. ${ }^{29-31} \mathrm{~A}$ significant advantage of hydrogels based on oligo(ethylene glycol) methyl ether methacrylate copolymers is the ability to precisely tune the thermoresponsive properties using co-monomers of different hydrophilicity. ${ }^{31-34}$ For instance, Lutz and coworkers 
copolymerized di(ethylene glycol) methyl ether methacrylate $\left(\mathrm{MEO}_{2} \mathrm{MA}\right)$ and oligoethylene glycol methyl ether methacrylate $\left(\mathrm{OEGMA}_{300}, M_{\mathrm{n}}=300 \mathrm{~g} \mathrm{~mol}^{-1}\right)$ containing different molar ratios of the two co-monomers, yielding POEGMA copolymers with LCSTs ranging from $27{ }^{\circ} \mathrm{C}$ to $65{ }^{\circ} \mathrm{C} .{ }^{33}$ Smeets et al. reported in situ gelling hydrogels based on POEGMA precursor functionalized with hydrazide/aldehyde functional groups. The resulting hydrogel possessed desirable biological properties of poly(ethylene glycol) (PEG) based hydrogels with tunable mechanical properties and degradation time. ${ }^{35}$ Hoare and coworkers extended their study by examining the effect of varying the degree of functionality of the precursor POEGMA polymers and length of PEG side chains on the stiffness, degradation rate, and gelation of injectable POEGMA hydrogels. ${ }^{10,36}$ They revealed that the properties of the gel could be tuned by changing the molecular weight of the precursor polymers. ${ }^{11}$ Hydrogels prepared with higher molecular weight precursor polymers possessed faster gelling times and higher compressive and shear moduli compared to gels prepared with lower molecular weight precursor polymers. Recently, they reported that the architecture of the precursor polymers (branching) could be used to tune the properties of injectable hydrogels. ${ }^{37}$ Hydrogels prepared using highly branched precursor polymers possessed faster gelation and higher stiffness than hydrogels prepared with linear precursors.

Weak mechanical properties of in situ gel forming hydrogels often limit their application. CNCs have been evaluated as reinforcing agents for a range of hydrogels ${ }^{38-44}$ due to their large aspect ratio, high stiffness, low cytotoxicity and ecotoxicological risk. ${ }^{45-47}$ Gicquel et al. ${ }^{48}$ investigated hydrogels produced from the adsorption of a block copolymer composed of poly(2-(dimethylamino)ethyl methacrylate) (PDMAEMA) cationic polyelectrolyte and poly(di(ethylene glycol)methyl ether methacrylate) ( $\left.\mathrm{PMEO}_{2} \mathrm{MA}\right)$ on oxidized cellulose nanocrystals. Upon heating beyond the LCST of a solution containing CNC and thermo-responsive copolymer, a transition from "liquid" to "gel" state occurred due to the network formation of CNC aggregates and non-adsorbed copolymers. McKee and coworkers ${ }^{43}$ reported a thermo-reversible hydrogel with tunable stiffness based on thermo-responsive methylcellulose (LCST around $50-60{ }^{\circ} \mathrm{C}$ ) and CNC. By increasing the temperature above the LCST of methylcellulose, a gel $\left(G^{\prime}>G^{\prime \prime}\right)$ with $G^{\prime}$ an order of magnitude larger than the liquid mixture of CNC and methylcellulose (below LCST of methylcellulose) was observed. De France et $a l^{49}$ prepared an in situ gelling hydrogel with tunable mechanical properties by physical incorporation of CNCs into the hydrazone crosslinked hydrazide/aldehyde functionalized POEGMA precursors. Strong interaction of the CNCs with POEGMA precursors led to the uniform dispersion of CNCs within the hydrogel, inducing physical crosslinking that significantly increased the stiffness of the gel. They reported up to 35 -fold increase in $G^{\prime}$ by adding $5 \mathrm{wt} \%$ of CNC to the hydrogel.

Acylhydrazone bond exhibits $\mathrm{pH}$-responsive characteristics, ${ }^{23,50}$ where the bond forms slowly in neutral condition, and the kinetics of bond formation accelerate in the presence of catalytic amounts of acid. ${ }^{51}$ The $\mathrm{pH}$ of surrounding medium has a large influence on the thermo-mechanical properties and self-healing behavior of the hydrogels prepared with acylhydrazone bonds. ${ }^{21}$

In this study, we prepared an in situ gelling hydrogel via acylhydrazone bonds using a mixture of hydrazide-functionalized POEGMA (POEGMA-H) and dialdehyde-functionalized CNC (DACNC). The rheological properties of the hydrogel can be tuned by changing the concentration of DACNC. Since POEGMA is a thermo-responsive polymer with a defined LCST, the mechanical properties of the hydrogel depended on the phase transition induced by changes in the temperature, and the dynamic nature of the acylhydrazone bonds imparts selfhealing properties to the hydrogel. We investigated the effect of $\mathrm{pH}$ on the self-healing characteristics and mechanical properties of the hydrogel, and these hydrogels are suitable for biomedical applications.

\section{Experimental}

\subsection{Materials}

Cellulose nanocrystals (CNCs) were provided by CelluForce Inc. Sodium periodate $\left(\mathrm{NaIO}_{4}, \geq 99.8 \%\right.$, Sigma-Aldrich), ethylene glycol (99.8\%, Sigma-Aldrich), anhydrous tetrahydrofuran (>99.5\%, TCI), thriethylamine (TEA, $\geq 99 \%$, Sigma-Aldrich), $\alpha$-bromoisobutyryl bromide (BiBB, 98\%, Sigma-Aldrich), sodium carbonate ( $\geq 99.0 \%$, Sigma-Aldrich), dichloromethane (DCM, $\geq 99.8 \%$, Sigma-Aldrich), anhydrous magnesium sulfate (Fisher), hydroxylamine hydrochloride $\left(\mathrm{NH}_{2} \mathrm{OH} \cdot \mathrm{HCl}, 99 \%\right.$, SigmaAldrich), sodium hydroxide ( $\mathrm{NaOH}, \geq 98 \%$, Sigma-Aldrich), di(ethylene glycol) methyl ether methacrylate $\left(\mathrm{MEO}_{2} \mathrm{MA}\right.$, 95\%, Aldrich), oligoethylene glycol methyl ether methacrylate (OEGMA ${ }_{300}, 95 \%$, Aldrich), copper(II) bromide $\left(\mathrm{CuBr}_{2}, 99 \%\right.$, Aldrich), 2,2'-bipyridyl (bPy, $\geq 99 \%$, Sigma-Aldrich), L-ascorbic acid (99\%, Sigma-Aldrich), methacrylic acid (MAA, 99\%, SigmaAldrich), adipic acid dihydrazide (ADH, >99\%, TCI), $N$-(3-dimethylaminopropyl)- $N^{\prime}$-ethylcarbodiimide (EDC, $\geq 98 \%$, SigmaAldrich), and dimethyl sulfoxide- $\mathrm{d}_{6}\left(\mathrm{C}_{2} \mathrm{D}_{6} \mathrm{OS}, 99.9 \%\right.$, Aldrich) were used as received.

\subsection{Periodate oxidation of $\mathrm{CNC}$}

Dialdehyde groups were formed on the CNC surfaces via sodium periodate oxidation. Sodium periodate ( $8 \mathrm{~g}$ ) was added to $400 \mathrm{~mL}$ of $0.25 \mathrm{wt} \% \mathrm{CNC}$ suspension and the $\mathrm{pH}$ was adjusted to 3.5 using glacial acetic acid. The suspension was heated to $45{ }^{\circ} \mathrm{C}$ in a one-neck round-bottom flask covered with aluminum foil (to avoid exposure to light), and stirred for $2.5 \mathrm{~h}$ in a dark fume hood. In the next step, $20 \mathrm{~mL}$ ethylene glycol was added to decompose the remaining periodate to iodate, and after $10 \mathrm{~min}$, the suspension was cooled to room temperature. After three cycles of centrifugation, the suspension was dialyzed against $\mathrm{DI}$ to $\mathrm{pH}=6$ and stored in a refrigerator at $4{ }^{\circ} \mathrm{C}$.

The aldehyde content of DACNCs was determined by the titration of generated acid from the reaction of $\mathrm{NH}_{2} \mathrm{OH} \cdot \mathrm{HCl}$ with aldehyde groups using sodium hydroxide. ${ }^{52}$ Briefly, $0.0125 \mathrm{~g}$ DACNC was dissolved in $10 \mathrm{~mL}$ DI water and the $\mathrm{pH}$ was adjusted 
to 5 using $\mathrm{NaOH}$ solution. A solution of $\mathrm{NH}_{2} \mathrm{OH} \cdot \mathrm{HCl}(10 \mathrm{~mL}$, $0.05 \mathrm{~g} \mathrm{~L}^{-1}$ ) was then prepared and the $\mathrm{pH}$ was adjusted to $5 \mathrm{using}$ $\mathrm{NaOH}$ solution. After mixing the DACNC suspension with $\mathrm{NH}_{2} \mathrm{OH} \cdot \mathrm{HCl}$ and incubated for $4 \mathrm{~h}$ at $40{ }^{\circ} \mathrm{C}$, the titration was then performed using $0.01 \mathrm{M} \mathrm{NaOH}$ solution. The amount $\mathrm{NaOH}$ solution to achieve a $\mathrm{pH}$ of 5 was recorded, and this was repeated for CNC suspension. The aldehyde content was then calculated using eqn (1):

$$
\text { Aldehyde content }(\%)=\frac{162 \times C \times\left(V_{2}-V_{1}\right)}{2000 \times M} \times 100
$$

where $C$ is the concentration of $\mathrm{NaOH}$ titrant $(\mathrm{M}), V_{1}$ is the amount of $\mathrm{NaOH}$ solution consumed by DACNCs $(\mathrm{mL}), V_{2}$ is the amount of $\mathrm{NaOH}$ solution consumed by CNCs $(\mathrm{mL})$, and $M$ is the weight of DACNC and CNC samples (g).

\subsection{Synthesis of ethylene bis(2-bromoisobutyrate) (2f-BiB) bifunctional initiator.}

Ethylene glycol $(1.8 \mathrm{~mL})$ and TEA $(9.90 \mathrm{~mL})$ were added to a round-bottom flask placed in an ice bath and purged with nitrogen for $15 \mathrm{~min}$. Anhydrous THF $(150 \mathrm{~mL})$ was added to the flask and purged for $15 \mathrm{~min}$, and cooled to $0{ }^{\circ} \mathrm{C}$. Under a nitrogen atmosphere, $8.4 \mathrm{~mL}$ BiBB was added dropwise via a pressure funnel. After vigorous shaking, the solution was stirred overnight at ambient temperature. The reaction mixture was then filtered to remove the triethylammonium bromide salt formed during the reaction and then concentrated using a rotary evaporator. The bright brown solution was then mixed with $10 \mathrm{~mL}$ sodium carbonate solution $(0.1 \mathrm{M})$ to hydrolyze any remaining BiBB. The product was then extracted with DCM and dried with anhydrous magnesium sulfate and filtered. The solvent was then removed by rotary evaporation. After three recrystallization steps in methanol, a yellowish white crystal was produced.

\subsection{Synthesis of poly(oligoethylene glycol methyl ether methacrylate-co-methacrylic acid) (POEGMA-MAA)}

POEGMA-MAA was synthesized via atom transfer radical polymerization using activators generated by electron transfer (AGET ATRP). In a two-neck round-bottom flask connected to a pressure funnel, $79 \mathrm{mg}$ of $2 \mathrm{f}-\mathrm{BiB}(0.22 \mathrm{mmol})$ was dispersed in a mixture of methanol and water $(20 \mathrm{~mL}$ methanol $+5 \mathrm{~mL}$ water). $\mathrm{MEO}_{2} \mathrm{MA}(8 \mathrm{~mL}, 44 \mathrm{mmol}), \mathrm{OEGMA}_{300}(12.4 \mathrm{~mL}$ $44 \mathrm{mmol})$, bPy (755.8 $\mathrm{mg}, 4.84 \mathrm{mmol})$, and L-ascorbic acid (38.7, $0.22 \mathrm{mmol}$ ) were then added to the flask and purged with nitrogen for $30 \mathrm{~min}$. A solution of $\mathrm{CuBr}_{2}(4.9 \mathrm{~mL}$ of $100 \mathrm{mg} \mathrm{mL} \mathrm{m}^{-1}$ ) was then added to the pressure funnel and purged with nitrogen for $15 \mathrm{~min}$ before dropwise addition to the flask. The temperature was raised to $55{ }^{\circ} \mathrm{C}$ and after $4 \mathrm{~h}$, $742 \mu \mathrm{L}$ of MAA ( $8.8 \mathrm{mmol}$, purged with nitrogen for $15 \mathrm{~min}$ ) was added to the flask through a pressure funnel and stirred overnight. The final molar ratio of ingredients was $\left[\mathrm{MEO}_{2} \mathrm{MA}\right] /$ $\left[\mathrm{OEGMA}_{300}\right] /[\mathrm{MAA}] /[2 \mathrm{f}-\mathrm{BiB}] /\left[\mathrm{CuBr}_{2}\right] /[\mathrm{bpy}] /[\mathrm{L}$-ascorbic acid $]=200 /$ $200 / 40 / 1 / 10 / 22 / 1$. The polymer was purified in a dialysis tubing (MWCO 3500 Da, Fisher) against DI water/acetone mixture (1:1)
Table 1 Recipes of in situ hydrogels

\begin{tabular}{lllll}
\hline & $\begin{array}{l}\text { Volume of } \\
\text { POEGMA-H } \\
20 \text { wt\% } \\
\text { solution }(\mu \mathrm{L})\end{array}$ & $\begin{array}{l}\text { Volume of } \\
\text { DACNC } \\
\text { suspension } \\
(\mu \mathrm{L})\end{array}$ & $\begin{array}{l}\text { Concentration } \\
\text { of DACNC } \\
\text { suspension } \\
(\mathrm{wt} \%)\end{array}$ & $\mathrm{pH}$ \\
\hline Gel3M & 200 & 200 & 3 & Medium \\
Gel2.25M & 200 & 200 & 2.25 & Medium \\
Gel1.5M & 200 & 200 & 1.5 & Medium \\
Gel3L & 200 & 200 & 3 & Low \\
Gel3H & 200 & 200 & 3 & High \\
\hline
\end{tabular}

for 3 days, followed by DI for 3 days and freeze dried. POEGMA was synthesized with the similar procedure without adding MAA.

\subsection{Hydrazide functionalization of POEGMA-MAA (POEGMA-H)}

Dried POEGMA-MAA (1 g) was dissolved in $10 \mathrm{~mL}$ DI water and $769.2 \mathrm{mg}$ of $\mathrm{ADH}$ (10 fold molar excess) was added to the solution. The $\mathrm{pH}$ of solution was reduced to 4.75 using $1 \mathrm{M} \mathrm{HCl}$. EDC (295.2 $\mathrm{mg}, 3.5$ fold molar excess) was then added and the $\mathrm{pH}$ of solution was kept at 4.75 by adding $1 \mathrm{M} \mathrm{HCl}$ and stirred overnight. The functionalized-polymer was purified in a dialysis tubing (MWCO $3500 \mathrm{Da}$, Fisher) against DI water for 3 days and freeze dried.

\subsection{Formation of in situ hydrogels}

Dry POEGMA-H polymer was dissolved in DI water to achieve a concentration of $20 \mathrm{wt} \%$. DACNC suspension was concentrated to $3 \mathrm{wt} \%$ using a centrifuge filter tube (MWCO $10000 \mathrm{Da}$, Merck Millipore Amicon). In order to prepare gels of different pHs, equal volumes of POEGMA-H solution and DACNC suspension $(200 \mu \mathrm{L})$ were thoroughly mixed and the $\mathrm{pH}$ was adjusted to low $(\sim 3)$, medium $(\sim 4)$ and high $(\sim 11)$ values by adding one drop $(\sim 10 \mu \mathrm{L})$ of $0.1 \mathrm{M} \mathrm{HCl}, 0.01 \mathrm{M} \mathrm{HCl}$, and $0.1 \mathrm{M} \mathrm{NaOH}$ solutions, respectively. The solutions were then allowed to gel overnight in sealed containers. In studying the effect of DACNC concentration, DACNC suspensions with concentration of $1.5 \mathrm{wt} \%$ and $2.25 \mathrm{wt} \%$ were used in the hydrogel preparation and the $\mathrm{pH}$ was adjusted to a pH of 4 by adding one drop $(\sim 10 \mu \mathrm{L})$ of $0.01 \mathrm{M}$ HCl. Table 1 summarizes the preparation recipe of the hydrogels and the nomenclature, GelXY was used, where $X$ is the concentration of DACNC suspension in wt $\%$ and $Y$ describes the $\mathrm{pH}$ condition with $\mathrm{L}, \mathrm{M}$, and $\mathrm{H}$ for low, medium, and high respectively.

\subsection{Characterization}

The zeta potential, size and distribution of DACNCs were determined using a Malvern Zetasizer Nano ZS90. ${ }^{1} \mathrm{H}$ NMR was performed on a Bruker $300 \mathrm{MHz}$ spectrometer at room temperature in DMSO-d $\mathrm{d}_{6}$. A Nicolet 6300 Fourier-transform infrared (FTIR) spectrometer was employed to obtain the FTIR spectra. Samples were mixed with $\mathrm{KBr}$ powder and pressed to pellets for the measurements with a wave number range set at 4000$500 \mathrm{~cm}^{-1}$ and a resolution of $1 \mathrm{~cm}^{-1}$. A total of 32 scans were accumulated to reduce the spectra noise. The thermal responsive properties of the polymers were investigated using a MicroDifferential Scanning Calorimetry ( $\mu \mathrm{DSC}$ ) (Microcal VP-DSC) and a temperature-controlled UV-Visible spectrophotometer (UV-vis) (Cary 100 Bio). The polymer solutions with a concentration of 


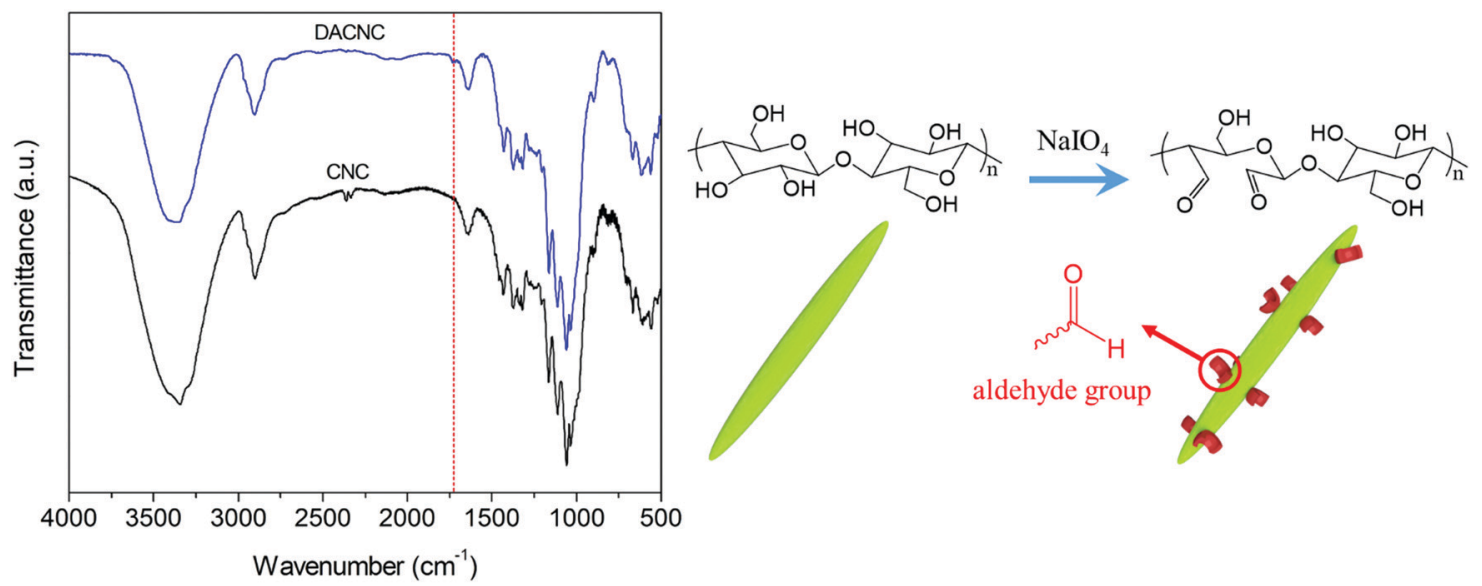

Fig. 1 FTIR spectra of CNC and DACNC and the reaction route for periodate oxidation of CNC.

$5 \mathrm{mg} \mathrm{mL} \mathrm{m}^{-1}$ were heated from $25{ }^{\circ} \mathrm{C}$ to $75{ }^{\circ} \mathrm{C}$ at $1{ }^{\circ} \mathrm{C} \mathrm{min}^{-1}$ rate in the $\mu$ DSC. A fixed wavelength $(500 \mathrm{~nm})$ was passed through the polymer solutions $\left(5 \mathrm{mg} \mathrm{mL}^{-1}\right)$ in UV-vis spectrophotometer as they were heated from $25{ }^{\circ} \mathrm{C}$ to $75{ }^{\circ} \mathrm{C}$ at $1{ }^{\circ} \mathrm{C} \min ^{-1}$ rate. The rheological properties of the hydrogel were characterized on a Malvern Kinexus ultra+ rheometer with a $25 \mathrm{~mm}$ parallel plate geometry and a solvent trap.

\section{Results and discussion}

DACNCs were prepared via periodate oxidation of CNCs, where the emergence of a new peak at $1730 \mathrm{~cm}^{-1}$ (vibration of $\mathrm{C}=\mathrm{O}$ group $)^{52}$ confirmed the formation of aldehyde groups on the CNCs (Fig. 1). The average zeta-potential and hydrodynamic diameter of pristine $\mathrm{CNC}$ were $-52.6 \pm 0.3 \mathrm{mV}$ and $95.0 \pm$ $1.8 \mathrm{~nm}$ respectively. After periodate oxidation the zeta-potential decreased to $-41.1 \pm 0.3 \mathrm{mV}$, while the hydrodynamic diameter remained constant $(97.8 \pm 3.5 \mathrm{~nm})$, confirming the preservation of the morphology of CNCs. The aldehyde content as a percentage of hydroxyl groups on CNC was determined to be $12.8 \%$.

The synthesis of $2 \mathrm{f}-\mathrm{BiB}$ was confirmed by ${ }^{1} \mathrm{H}$ NMR and FTIR, and Fig. 2a depicts the ${ }^{1} \mathrm{H}$ NMR spectrum of $2 \mathrm{f}-\mathrm{BiB}$ and its associated peaks $\left(\delta=4.37 \mathrm{ppm}, \mathrm{s}, 4 \mathrm{H}, \mathrm{RO}-\left(\mathrm{CH}_{2}\right)_{2}-\mathrm{OR}\right.$ and $\left.\delta=1.87, \mathrm{~s}, 12 \mathrm{H}, \mathrm{ppm},-\left(\mathrm{CH}_{3}\right)_{2}\right) .{ }^{53}$ The carbonyl stretching peak
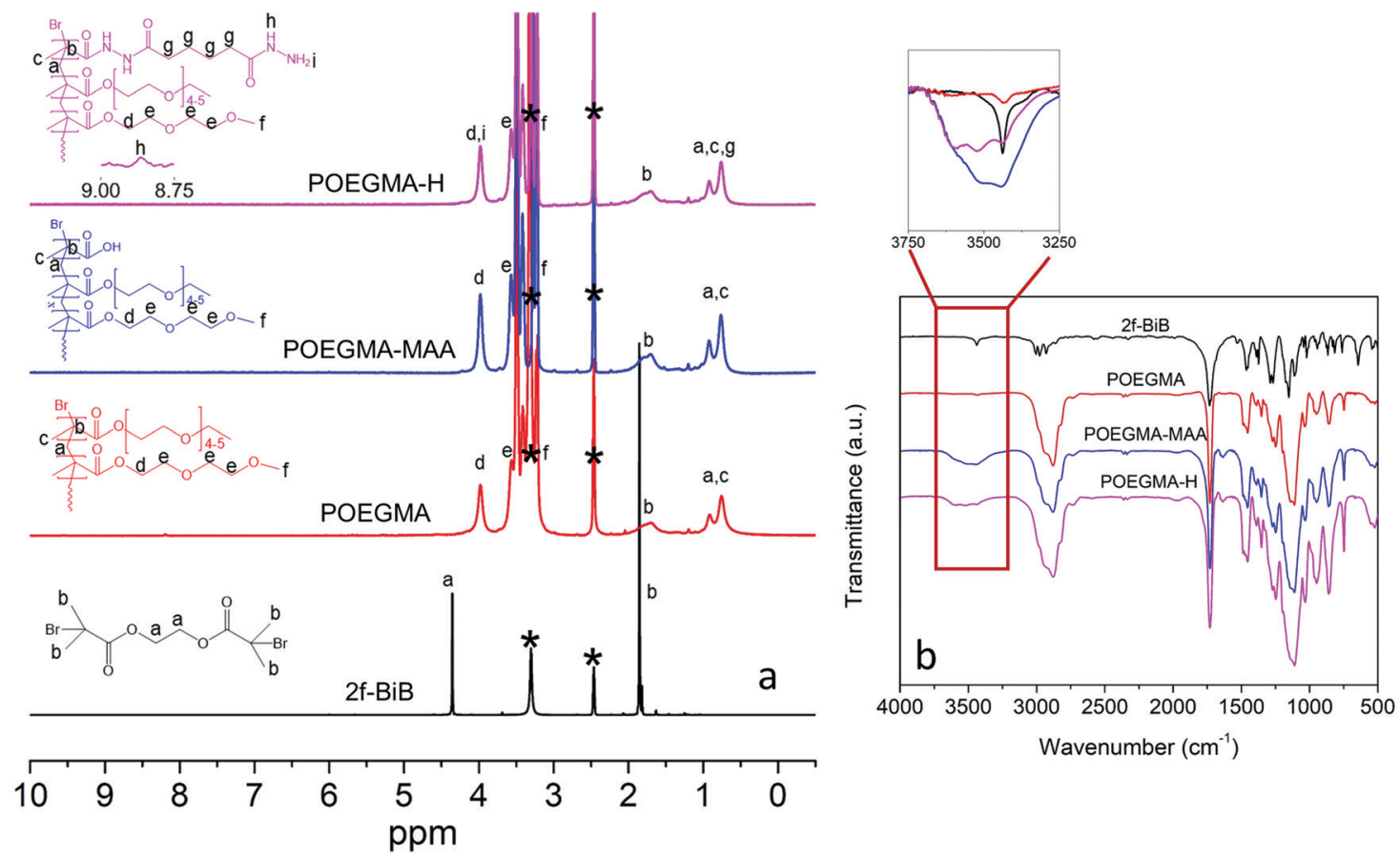

Fig. 2 (a) ${ }^{1} \mathrm{H}$ NMR spectra of 2f-BiB, POEGMA, POEGMA-MAA, and POEGMA-H in $\mathrm{C}_{2} \mathrm{D}_{6} \mathrm{OS}$. Peak assignments are based on the literature. ${ }^{54,59}$ Solvent peaks are marked with *. (b) FTIR spectra of 2f-BiB, POEGMA, POEGMA-MAA, and POEGMA-H. Inset shows the $-\mathrm{OH}$ stretching range $\left(3250 \mathrm{~cm}^{-1}\right.$ to $\left.3750 \mathrm{~cm}^{-1}\right)$. 


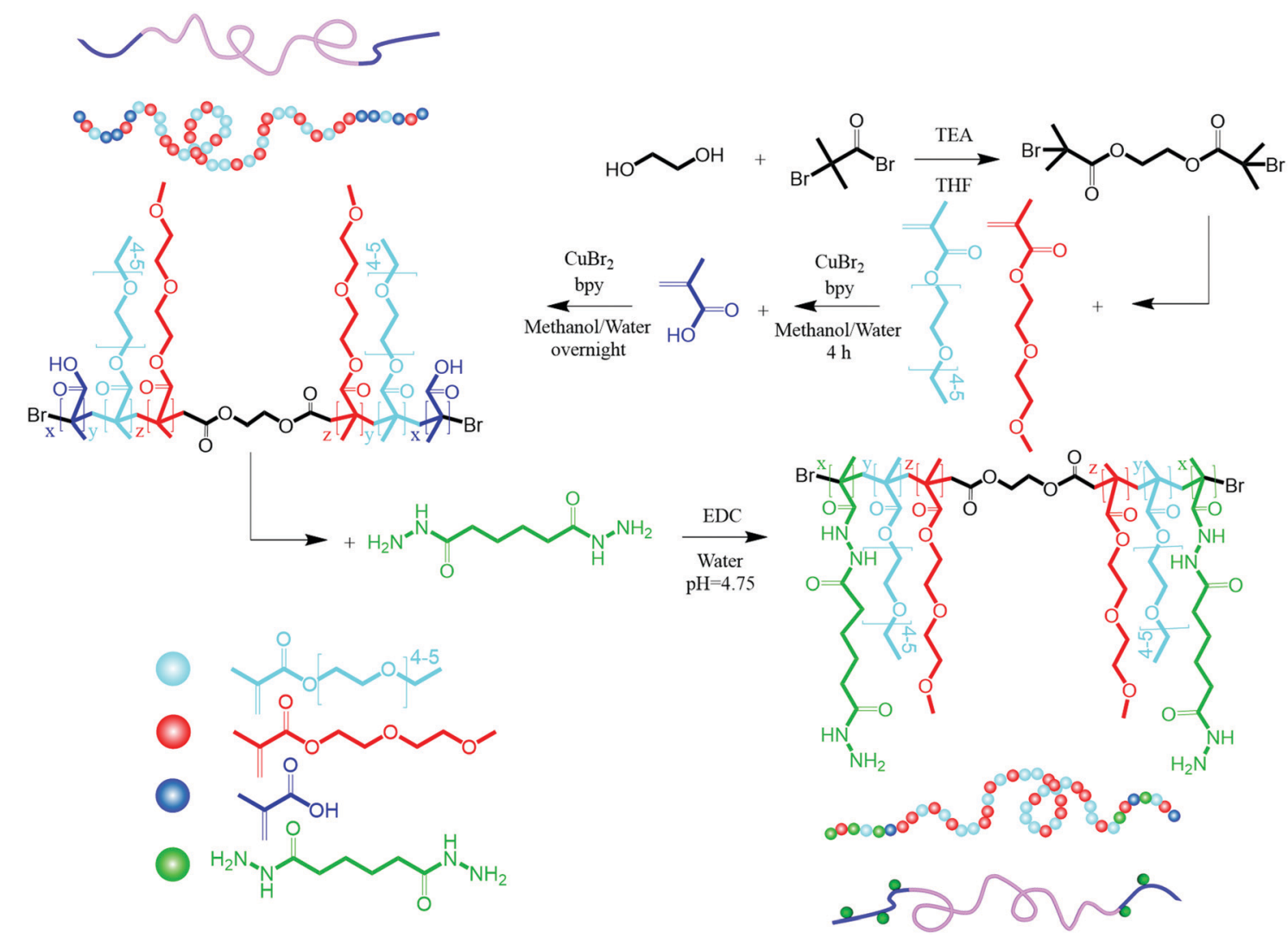

Scheme 1 Synthesis of 2f-BiB, POEGMA-MAA, and POEGMA-H.

at $1730 \mathrm{~cm}^{-1}$ in the FTIR spectrum of $2 \mathrm{f}-\mathrm{BiB}$ also confirmed the success of the synthesis ${ }^{53}$ (Fig. 2b). POEGMA-MAA was synthesized by a two-step AGET ATRP polymerization from 2f-BiB bifunctional initiator and subsequently functionalized with $\mathrm{ADH}$ through the carboxyl groups of MAA via the EDC chemistry $^{11}$ as shown in Scheme 1 . The copolymerization conversion was $\sim 10 \%$ and the molecular weight was $\sim 10 \mathrm{kDa}$ (details in ESI $\dagger$ ). The characteristic ${ }^{1} \mathrm{H}$ NMR spectrum of POEGMA-H confirmed the presence of hydrazide groups in the copolymer $\left(\delta=8.87 \mathrm{ppm}, \mathrm{s},-\mathrm{NH}-\mathrm{NH}_{2}\right) \cdot{ }^{54}$ FTIR spectra of POEGMA, POEGMA-MAA and POEGMA-H displayed clear differences in the wavelength range of the $-\mathrm{OH}$ stretching $\left(3250 \mathrm{~cm}^{-1}\right.$ to $3750 \mathrm{~cm}^{-1}$ ) (inset in Fig. 2b). POEGMA showed a very small peak that is associated with the remaining $-\mathrm{OH}$ groups in 2f-BiB. After copolymerization with MAA, a broad peak emerged as a result of the carboxyl groups. By functionalizing POEGMA-MAA with hydrazide groups, the intensity and shape of this peak broadened and shifted to a higher wave number (Fig. 2b).

The thermo-responsive behavior of the copolymers was studied by UV-vis spectrometry and $\mu$ DSC. Due to the delicate balance between favorable and unfavorable interactions, POEGMA displayed a phase transition defined by its LCST in water. Upon increasing the temperature, the extensive hydrogen bonding between the ether groups on POEGMA and hydrogen atoms in water was disrupted, and the polyethylene glycol (PEG) segments on the POEGMA collapsed onto the methacrylate domains resulting in a coil to globule transition. ${ }^{32,55}$ Cloud point measurements by UV-vis spectrometry performed to determine the coil to globule transition temperature led to the higher scattering compared to the soluble chains. UV-vis spectrometry results indicated that POEGMA exhibited a single step phase transition with an onset temperature at $50{ }^{\circ} \mathrm{C}$ in accordance with reported value $^{33}$ (Fig. 3a).

By adding the MAA units to the POEGMA chains, the copolymer displayed a two-step phase transition. The onset temperature for the first transition shifted to a lower temperature $\left(49^{\circ} \mathrm{C}\right)$ while the second transition commenced at a higher temperature $\left(55^{\circ} \mathrm{C}\right)$ compared to only POEGMA. The lower phase transition temperature could be due to inter-molecular hydrogen bonding and complexation between carboxyl groups of MAA and ether groups on the PEG pendants that disrupts the hydrogen bonding between the PEGs and water molecules. ${ }^{56-58}$ The two-step phase transition reflects the presence of two different blocks in the copolymer with two different LCSTs. ${ }^{59,60}$ As discussed earlier, MAA monomer was added to the reaction after $4 \mathrm{~h}$.

As $\mathrm{MEO}_{2} \mathrm{MA}$ and $\mathrm{OEGMA}_{300}$ monomers were present in the reaction medium, the end blocks consisted of $\mathrm{MEO}_{2} \mathrm{MA}$ and OEGMA $_{300}$ and MAA random copolymers (with higher amount 

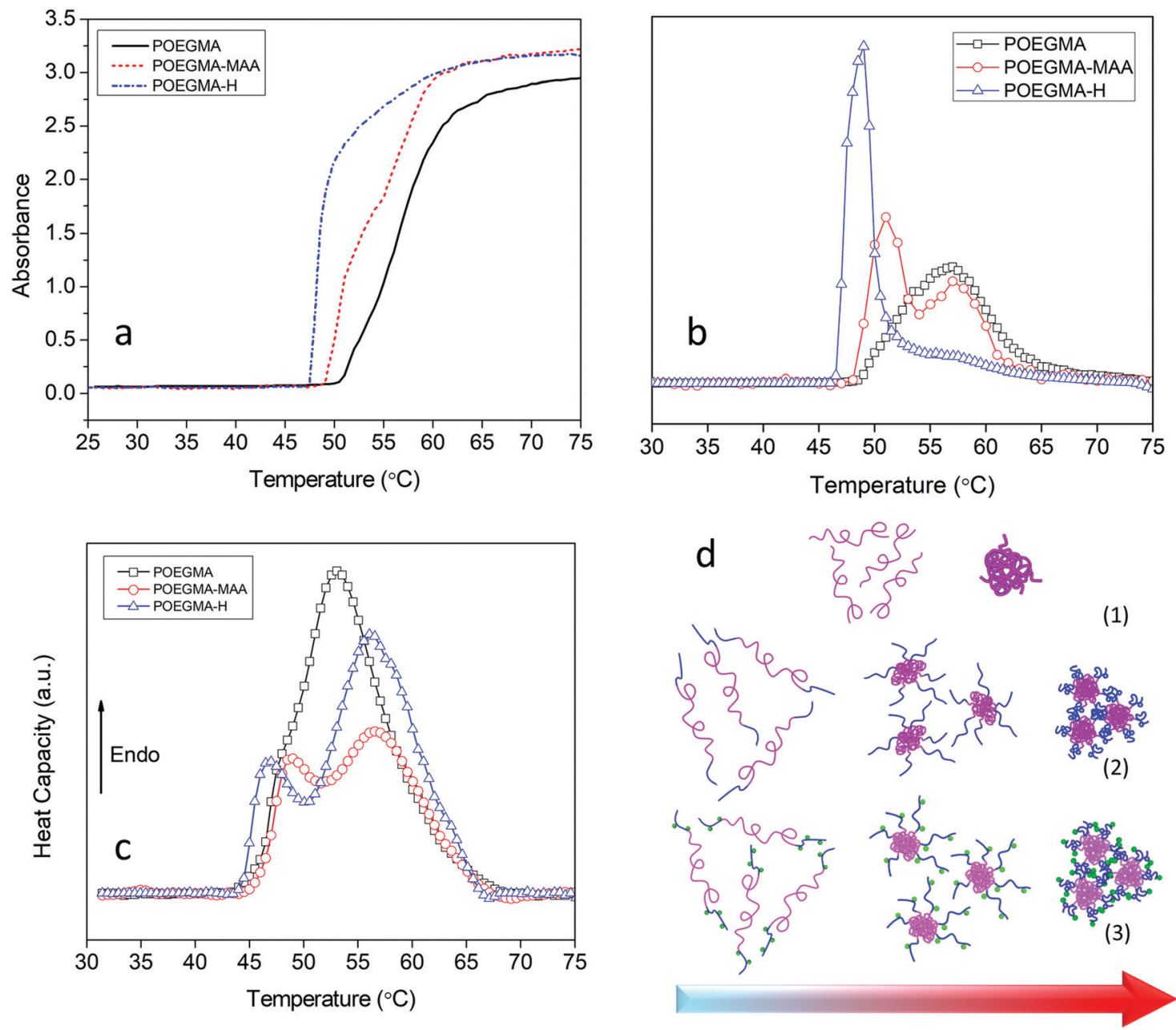

Fig. 3 (a) UV-vis spectrum at $500 \mathrm{~nm}$ versus temperature of POEGMA, POEGMA-MAA, and POEGMA-H aqueous solutions (5 mg $\mathrm{mL}^{-1}$ ). (b) Derivative of UV-vis data for more convenient visualization of two-step phase transitions. (c) $\mu \mathrm{DSC}$ curves of aqueous solutions $\left(5 \mathrm{mg} \mathrm{mL}^{-1}\right.$ ) of POEGMA, POEGMAMAA, and POEGMA-H. (d) Proposed mechanism for phase separation of (1) POEGMA, (2) POEGMA-MAA, and (3) POEGMA-H in aqueous solutions upon heating.

of MAA compare to other two monomers, Scheme 1). Due to the presence of a more hydrophilic monomer (MAA) in these blocks, the phase transition temperature became higher. The same two-step phase transition was observed for POEGMA-H with the first phase transition occurring at $46{ }^{\circ} \mathrm{C}$ and the second at $55{ }^{\circ} \mathrm{C}$ (Fig. 3a and b). The smaller second peak in derivative of UV-vis data of POEGMA-H compared to POEGMAMAA (Fig. 3b) could be associated to the isolated smaller domains due to the higher hydrophilicity and affinity for water of the hydrazide groups compared to the carboxylic acid groups. The conformational changes due to the formation and breaking of hydrogen bonds between the copolymers and water involved a thermodynamic process that could be studied by $\mu$ DSC. The results of $\mu$ DSC also confirmed a single-step phase transition for POEGMA and two-step phase transition for POEGMA-MAA and POEGMA-H (Fig. 3c). The phase transition temperatures were observed at lower temperatures in all cases compared to the results from UV-vis spectroscopy. The reason for this difference is that DSC directly measures the fluctuations of heat flow associated with the phase separation, while, in UV-vis spectroscopy, the phase separation associated with the coil to globule transition and aggregation of the polymeric chains was determined from the turbidity, yielding a higher phase transition temperature. The proposed mechanism for the two-step phase transition of POEGMA-MAA and POEGMA-H is shown in Fig. 3d. At low temperatures, individual copolymer chains are present, and when the temperature was increased beyond the first phase transition temperature, core-shell micelles started to form and stabilize by the end-blocks. With further increase in the temperature beyond the second phase transition temperature, larger micelles were produced via the association of smaller micelles.

The effect of phase transition on the rheology of POEGMA-H aqueous solution was also evaluated. Fig. S1a (ESI $\dagger$ ) shows the temperature sweep of $20 \mathrm{wt} \%$ POEGMA-H aqueous solution at $1 \mathrm{~Hz}$ and $1 \%$ strain (within the linear viscoelastic region). At the temperature below the first phase transition temperature, the moduli displayed a small decrease with increasing temperatures. Above the first phase transition temperature, the loss modulus $G^{\prime \prime}$ 


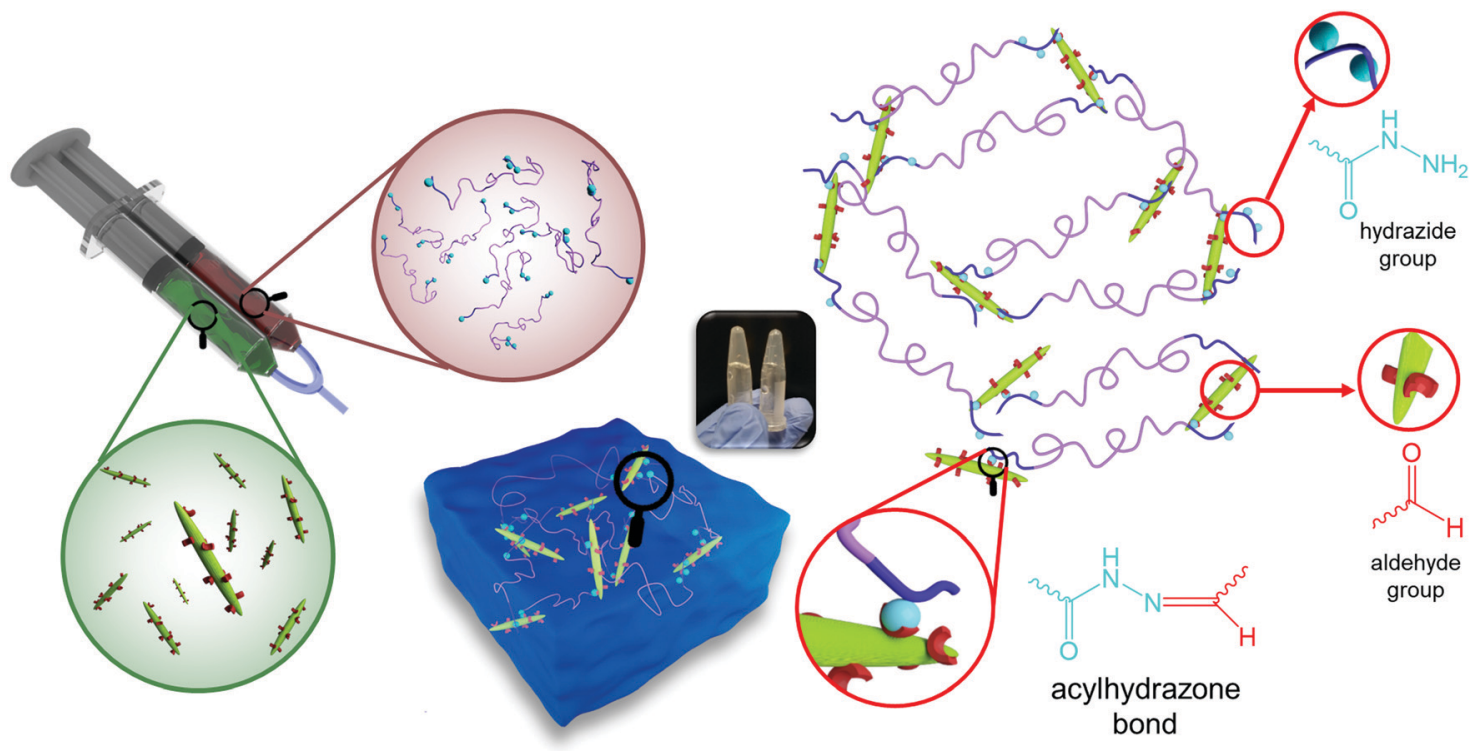

Fig. 4 Formation of in situ gelling hydrogel by reaction of hydrazide groups of POEGMA-H and aldehyde groups of DACNC.

was greater than storage modulus $G^{\prime}$, where the POEGMA-H solution was a viscous liquid. At the first phase transition temperature, the coil to globule transition of the middle blocks on POEGMA-H chains produced a larger $G^{\prime}$ and $G^{\prime \prime}$. A further increase of $G^{\prime}$ and $G^{\prime \prime}$ was observed with increasing temperature that is associated to the coil to globule transition of the end-blocks of the polymer chains (Fig. S1b, ESI $\dagger$ ). The hydrogels were formed by the bond formation between the hydrazide groups of POEGMA-H and aldehyde groups of DACNC (Fig. 4), which was confirmed by comparing the storage and loss modulus of POEGMA-H solution (20 wt $\%$ ), DACNC suspension ( $3 \mathrm{wt} \%$ ) and Gel3M measured at various temperatures at $1 \mathrm{~Hz}$ and $1 \%$ strain (Fig. 5a). The DACNC suspension displayed a monotonous decrease in the $G^{\prime}$ and $G^{\prime \prime}$ with temperature. However, in Gel3M, an abrupt increase in both $G^{\prime}$ and $G^{\prime \prime}$ was observed at the first phase transition temperature of POEGMA-H with $G^{\prime}$ being much larger than $G^{\prime \prime}$ over the entire temperature range, which confirmed the formation of a stable gel. The coil to globule transition of the middle and end-blocks of PEGMA-H is responsible for the increase in gel stiffness ${ }^{60}$ (Fig. 5b).

The effect of DACNC concentration on the rheological properties of hydrogel was examined. Fig. 6a shows the effect of DACNC concentration on the linear viscoelastic regime of the hydrogel at room temperature and $1 \mathrm{~Hz}$. Gel1.5M displayed a very narrow linear viscoelastic range, where the $G^{\prime}$ and $G^{\prime \prime}$ had the same magnitude, indicating the formation of a weak gel. By increasing the concentration of DACNC, the linear viscoelastic regime broadened significantly to $400 \%$ and $G^{\prime}$ was much larger than $G^{\prime \prime}$. The deviation from linearity is a result of the breakdown of the dynamic cross-linked hydrogel. ${ }^{12}$ Temperature sweep experiments were also conducted to investigate the effect of temperature on the rheological properties of the hydrogels containing different amounts of DACNC (Fig. 6b). By decreasing the DACNC concentration to 2.25, a two-step increase in both $G^{\prime}$ and $G^{\prime \prime}$ was observed (Fig. 6b). The second step might be attributed to the coil to globule transition and
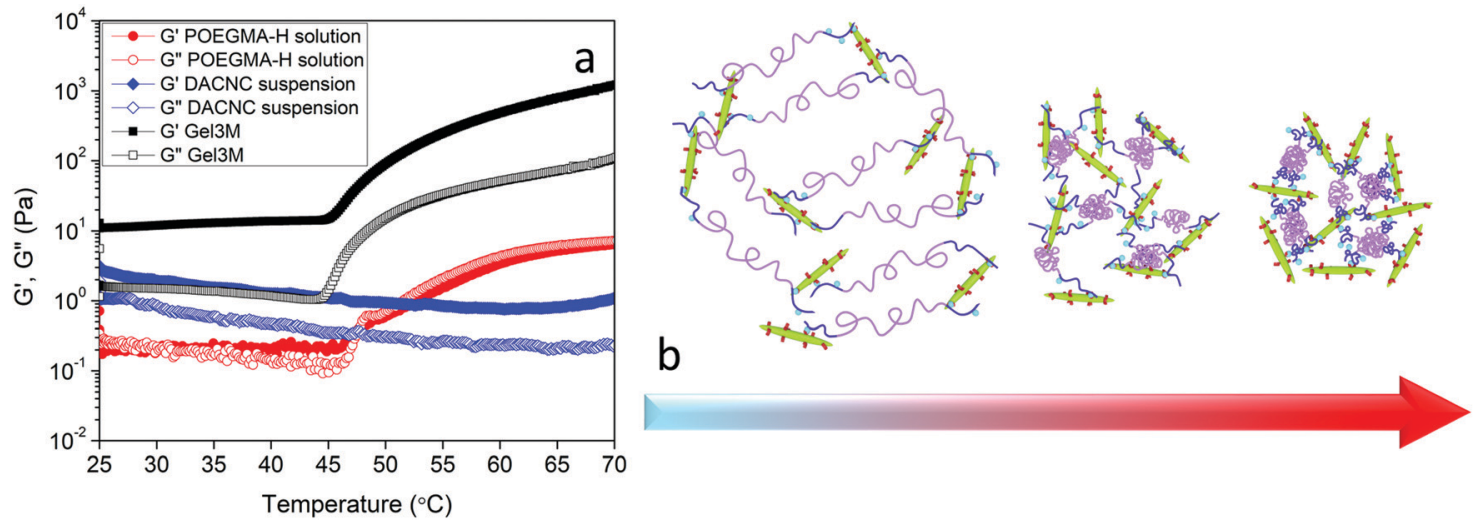

Fig. 5 (a) Storage and loss modulus of POEGMA-H solution, DACNC suspension, and Gel3M versus temperature at $1 \mathrm{~Hz}$ and $1 \%$ strain. (b) Schematic representation of coil to globule transition of middle and end blocks of POEGMA-H in presence of DACNC. 

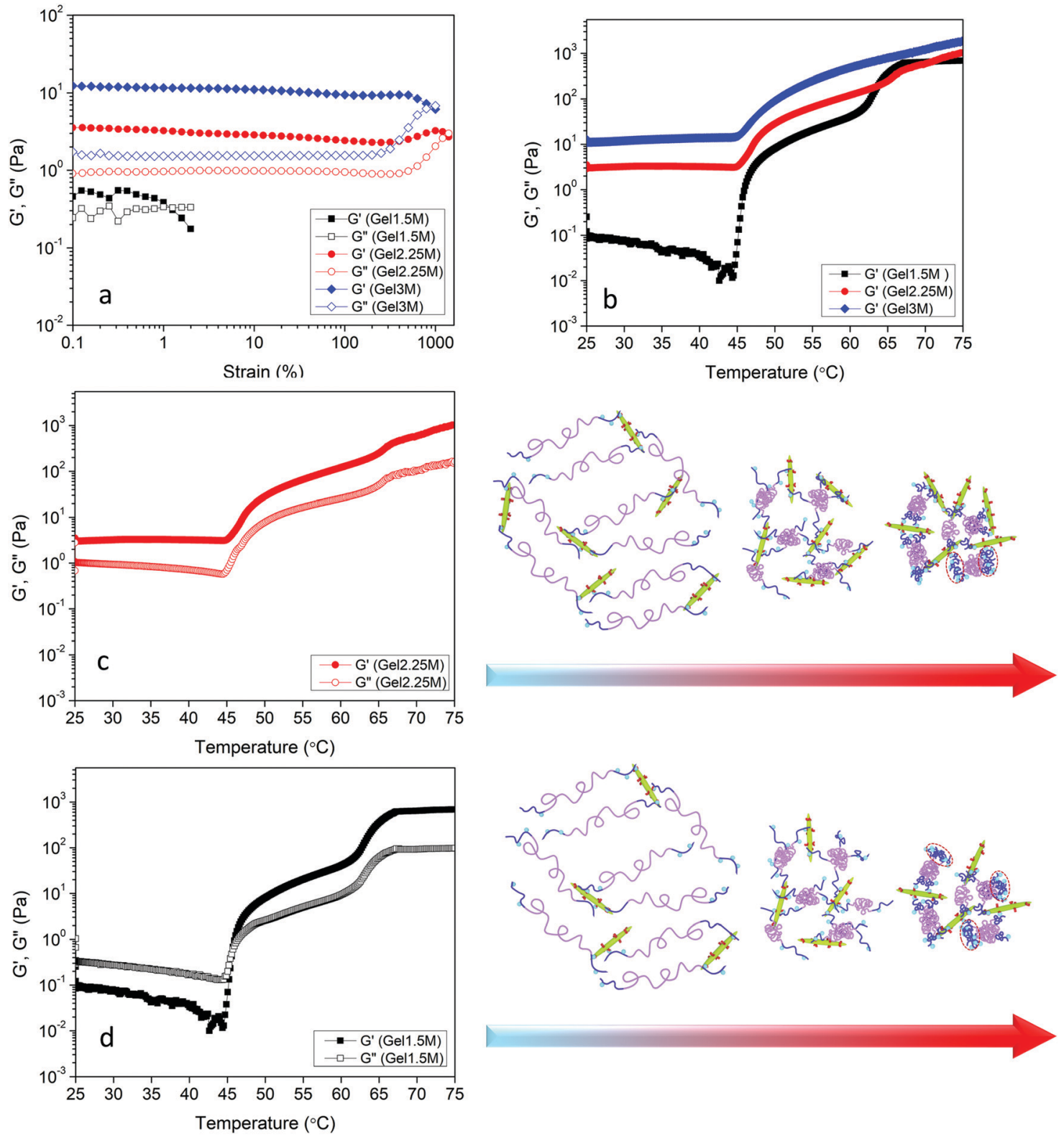

Fig. 6 (a) Strain amplitude sweep results of Gel1.5M, Gel2.25M, and Gel3M at fixed angular frequency $1 \mathrm{~Hz}$. (b) Storage modulus versus temperature of Gel1.5M, Gel2.25M, and Gel3M at $1 \mathrm{~Hz}$ and 1\% strain. Storage and loss modulus at $1 \mathrm{~Hz}$ and 1\% strain of (c) Gel2.25M and (d) Gel1.5M. Red dashed circled regions show aggregated globules of end blocks of PEGMA-H chains.

association of the end blocks of POEGMA-H chains that were free due to insufficient DACNC nanoparticles. The increase in the amplitude for the second step $\left(\sim 60-65{ }^{\circ} \mathrm{C}\right)$ of $G^{\prime}$ from $180 \mathrm{~Pa}$ in Gel2.25M to $550 \mathrm{~Pa}$ in Gel1.5M confirmed this hypothesis, since there were more unassociated end-blocks in Gel1.5M. The reason for the single-step transition of Gel3M could then be attributed to the absence of unassociated endblocks in this hydrogel. The temperature for the second step of $G^{\prime}$ was greater than the second phase transition temperature of POEGMA-H ( $55{ }^{\circ} \mathrm{C}$ measured by UV-vis and $\mu$ DSC) could be related to the association of the chains within the network structure or higher concentration of POEGMA-H in hydrogels compared to UV-vis and $\mu$ DSC samples. The second step of
$G^{\prime}$ shifted to lower temperatures when the concentration of DACNC was reduced. Similar changes in the phase transition temperature arising from the addition of nanoparticle was reported previously. ${ }^{61}$ Gel2.25M existed as a gel over the entire temperature range $\left(G^{\prime}>G^{\prime \prime}\right)$ while, Gel1.5M experienced a sol-gel transition at the first phase transition temperature of the POEGMA-H. After the formation of micelles due to the coil to globule transition of the middle blocks, unlike POEGMA-H solution only, DACNCs bridged the micelles leading to the formation of a network (Fig. 6d). Increasing the amount of DACNC enhanced the gel stiffness both at low temperatures (below the phase transition) and high temperatures (above the phase transition) (Fig. S2, ESI $\dagger$ ). 
A theoretical model based on the extensible worm-like model ${ }^{62,63}$ was employed to examine the rheological behavior of the hydrogels. This model considers the network as a collection of thermally fluctuating bundles of semi-flexible chains. Kouwer et $a l .{ }^{64}$ modified the existing model to describe the thermal behavior of the storage modulus of their polyisocyanopeptide hydrogels which is similar to the present study. The plateau modulus $G_{0}$ of a gel consisting of $N$ polymer chains is dependent on the persistence length of the chains at the reference temperature $l_{\mathrm{p}, 0}$ and the length $l_{\mathrm{c}}$ between crosslinks:

$$
G_{0}=\frac{6 l_{\mathrm{M}}}{M} N^{3} \frac{c}{l_{\mathrm{c}}} R T l_{p, 0}^{2} e^{2 \beta T}
$$

where $l_{\mathrm{M}}$ is the length per monomer unit projected along the polymer backbone, $M$ is the molecular weight of a monomer, $c$ is the concentration, $R$ is the gas constant, and $T$ is the absolute temperature. They introduced the phenomenological correction $e^{2 \beta T}$ to account for the exponential increase in the plateau modulus with temperature. They proposed that the increase of plateau modulus with temperature resulted from the stiffening of individual chains and since $G_{0}$ scales with $l_{\mathrm{p}, 0}^{2}$, the exponent also included a prefactor of 2 . Their experimental measurements revealed an exponential increase of persistence length of individual polymer chains with temperature with the same exponent $\beta, l_{\mathrm{p}} \propto e^{\beta T}{ }^{64}$ The exponent $\beta$ corresponds to the rate of stiffening of individual polymer chains in a narrow temperature range. Estimates of $\beta$ along with their associated temperature ranges are presented in the ESI $\dagger$ (Table S1) for Gel1.5M, Gel2.25M, and Gel 3M. Fig. 7 shows the exponential fits $\left(G_{0} \propto T e^{2 \beta T}\right)$ to experimental storage modulus data of Gel2.25M at different temperature ranges. Below the first phase transition temperature, the agreement between experimental data and model is not good, while above the first phase transition temperature, model predictions are in good agreement with the experimental data. Since the model was originally developed for semi-flexible polymers, a better agreement of storage modulus for the

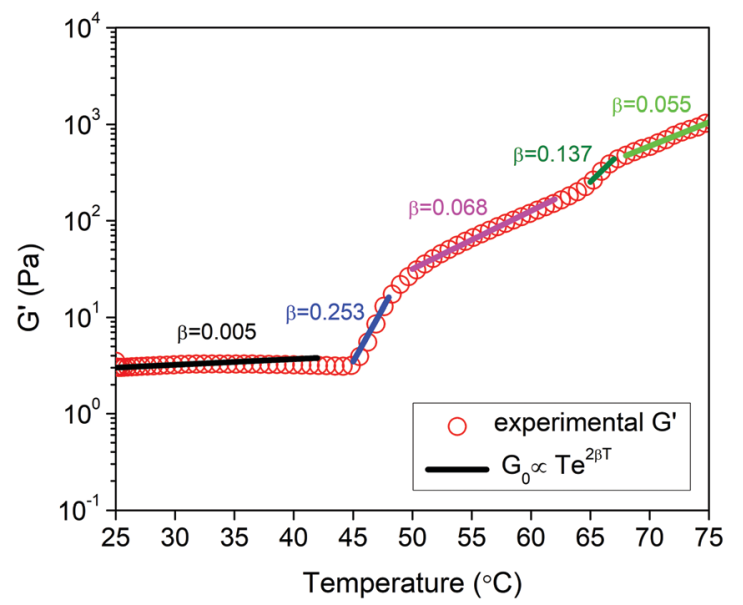

Fig. 7 Exponential fits to experimental storage modulus data of Gel2.25M. temperature above the phase transition temperature, where the polymer chains were stiffer due to the coil to globule transition is expected. The stiffening rates were higher in the phase transition regions compared to other regions (Fig. 7 and Table S1, ESI $\dagger$ ) indicating that coil to globule transitions of the middle and end blocks of POEGMA-H are the main factors for the chain stiffening. The value of $\beta$ during the first phase transition $\left(0.253\right.$ for $\left.45-47{ }^{\circ} \mathrm{C}\right)$ was higher compared to the second phase transition ( 0.137 for $\left.65-67{ }^{\circ} \mathrm{C}\right)$. This further correlated with the coil to globule transition of the two different blocks (middle and end blocks) of POEGMA-H at these two temperature ranges.

The effect of $\mathrm{pH}$ on the rheological properties of hydrogels was also investigated. First, the effect of $\mathrm{pH}$ on the phase transition of POEGMA-H aqueous solution was investigated (Fig. S3, ESI $\dagger$ ). Changing the $\mathrm{pH}$ appeared to have a minor effect on the temperature and shape of UV-vis spectra. Slight increase in the phase transition temperatures in acidic and basic conditions compared to neutral $\mathrm{pH}$ were observed for POEGMA-H. Similar increase of the phase transition temperature in acidic and basic pHs compared to $\mathrm{pH} 7$ was reported for POEGMA and this was attributed to the slightly stronger interactions between PEG side chains of POEGMA and hydroxide ions or hydronium protons compared to water. ${ }^{65}$ The linear viscoelastic regime of the hydrogel containing the highest content of DACNC was evaluated with respect to $\mathrm{pH}$ at room temperature and $1 \mathrm{~Hz}$ (Fig. S4, ESI $\dagger$ ). At low and medium pHs, the linear viscoelastic region of the hydrogels was broad (up to $400 \%$ ) with $G^{\prime}>G^{\prime \prime}$. The deviation from linearity is a result of the breakdown of the cross-links in the hydrogel. ${ }^{12}$ By increasing the $\mathrm{pH}$, the linear viscoelastic range was dramatically reduced to below $1 \%$ and $G^{\prime}$ and $G^{\prime \prime}$ were close, indicating the formation of a weak gel (Fig. S4, ESI†). Temperature sweep experiments at $1 \mathrm{~Hz}$ and $1 \%$ strain were also conducted to investigate the effect of $\mathrm{pH}$ on $G^{\prime}$ and $G^{\prime \prime}$. The storage modulus of Gel3L showed a single-step increase at the first phase transition temperature of POEGMA-H, behavior which resembled that of the Gel3M (Fig. 8a). The storage modulus of Gel3M below the phase transition was greater than that reported for Gel3L. The rate of formation of acylhydrazone bonds increased significantly with decreasing $\mathrm{pH}$ values, thus, the gelation occurred much faster at low $\mathrm{pH}$ leading to the formation of an irregular transient network. The lower gelation rate at medium $\mathrm{pH}$ facilitated the development of a more regular network closer to the equilibrium (Fig. 8a). At high pH condition, very slow gelation rate was observed, leading to a loose network compared to the low and medium pH conditions (Fig. 7a and Fig. S5, ESI†). Unlike low and medium pHs, a sol-gel transition was observed at the first phase transition temperature of the system at high $\mathrm{pH}$, where the formation of acylhydrazone bonds was inhibited, and only physical interactions were present in Gel3H. The micelle formation due to the coil to globule transition of the middle blocks of POEGMA-H chains at the first phase transition temperature and bridging of the micelles by DACNCs through physical interactions were responsible for the sol-gel transition. The second step in the moduli increase is associated 

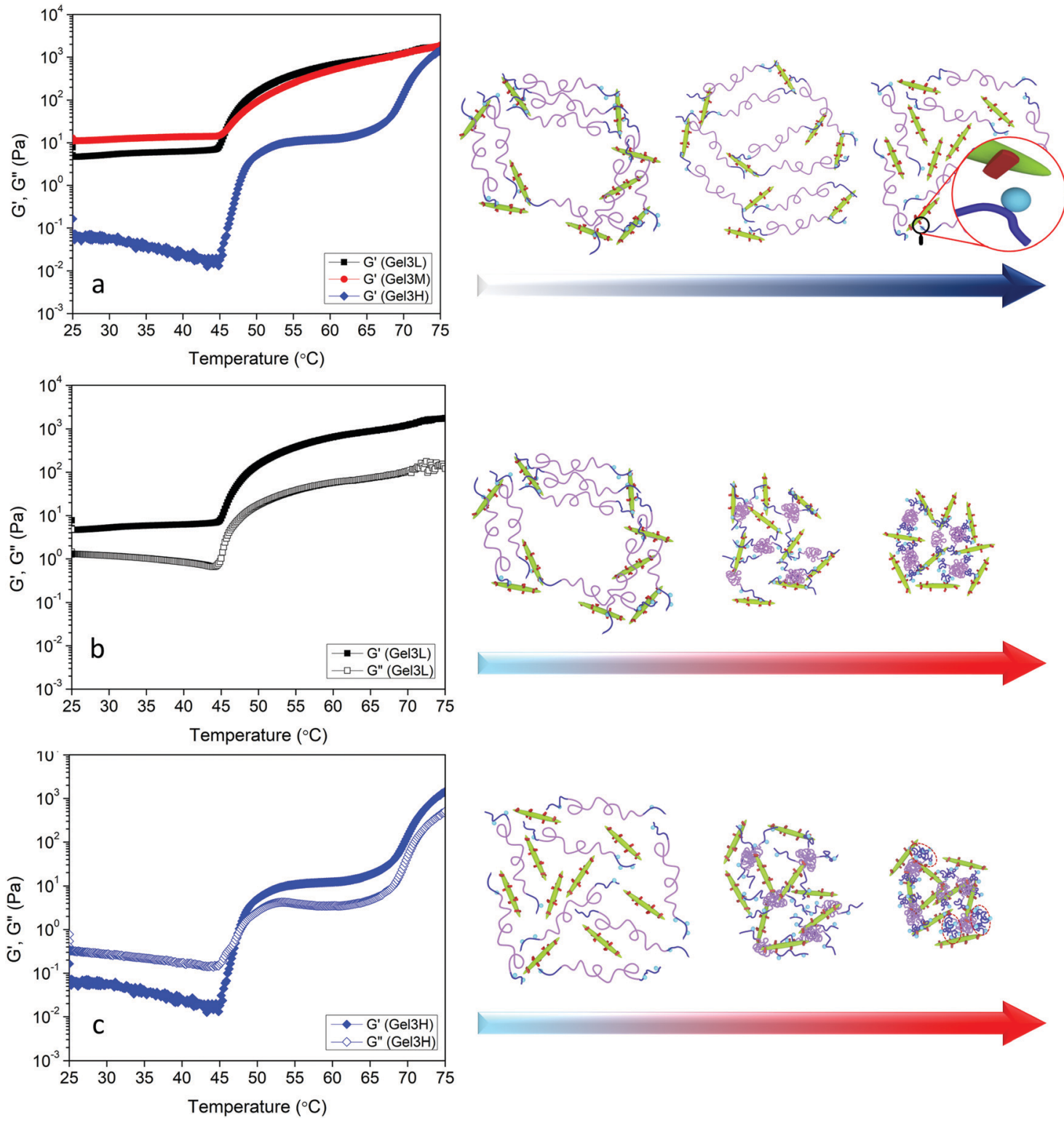

Fig. 8 (a) Storage modulus versus temperature of Gel3L, Gel3M, and Gel3H at $1 \mathrm{~Hz}$ and $1 \%$ strain. Storage and loss modulus at $1 \mathrm{~Hz}$ and $1 \%$ strain of (b) Gel3L and (c) Gel3H. Red dashed circled regions show aggregated globules of end blocks of PEGMA-H chains.

with the coil to globule transition of the end blocks of the chains due to the lack of acylhydrazone bond formation. This increase for Gel3H occurred at higher temperature compared to Gel1.5M and Gel2.25M that could be related to the higher concentration of DACNC ${ }^{61}$ and higher $\mathrm{pH}$ of the system (Fig. S3, ESI $\dagger$ ).

Rheological recovery tests were employed to evaluate the self-healing capability of the hydrogels. ${ }^{17,19,50}$ Measurements of the linear viscoelastic regime of the hydrogels revealed the critical strain where the dynamic network of hydrogels was destroyed (Fig. S4, ESI $\dagger$ ). In order to assess the restoration of the hydrogel network after destruction, step-strain tests were conducted at a fixed angular frequency $1 \mathrm{~Hz}$ (Fig. 9a). When the Gel3M was subjected to a small strain in the linear viscoelastic region $(1 \%)$ for $100 \mathrm{~s}, G^{\prime}$ was greater than $G^{\prime \prime}$, and they remained constant over the duration of the tests, indicating a stable hydrogel. By increasing the strain to a value greater than the linear viscoelastic threshold $(2000 \%)$ for $100 \mathrm{~s}, G^{\prime \prime}$ became larger than $G^{\prime}$ indicating that the hydrogel was liquefied. After $100 \mathrm{~s}$ rest, the strain was reduced to $1 \%$ again, and as a result, hydrogel was reformed $\left(G^{\prime}>G^{\prime \prime}\right)$ and storage modulus was completely recovered. This cycle was repeated 2 more times to ensure the reproducibility of the results (Fig. 8a). The effect of $\mathrm{pH}$ was also studied on the self-healing behavior of the hydrogel. Similar step-strain experiments were performed on Gel3L and Gel3H. For Gel3H, the second strain was $20 \%$ that was much greater than the linear viscoelastic threshold (Fig. S4, ESI $\dagger$ ). Interestingly, the storage modulus of Gel3L was increased via reformation after the network was disrupted (Fig. 9b). This might be due to the attainment of a more regular network that was closer to equilibrium after each destruction and reformation 

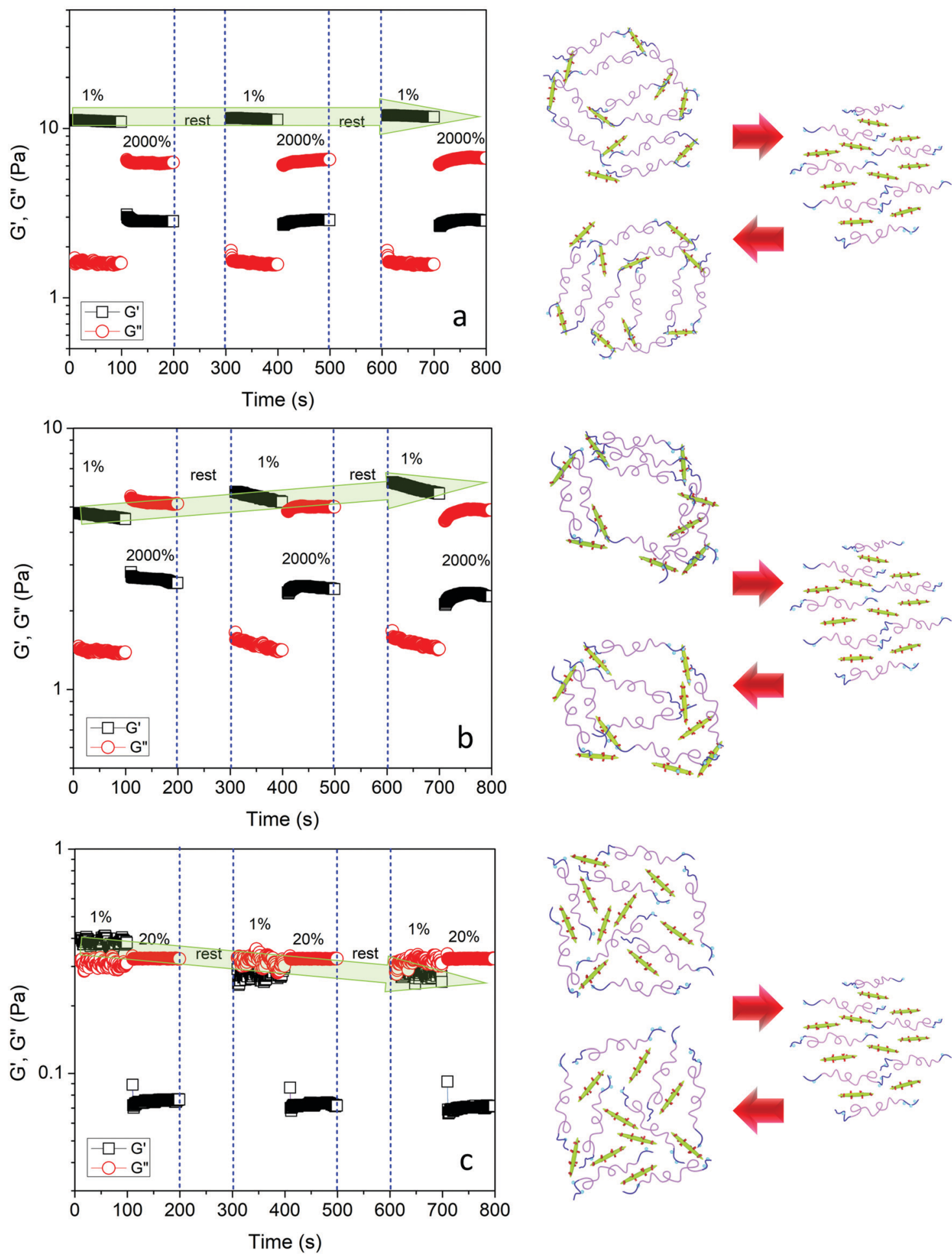

Fig. 9 Step-strain experiments by switching from small strain (1\%) to large strain (2000\% or $20 \%$ ) at a fixed angular frequency $1 \mathrm{~Hz}$ along with the schematic representation of the experiment for (a) Gel3M, (b) Gel3L, and (c) Gel3H.

of the network as schematically represented in Fig. 9b. However, for $\mathrm{Gel} 3 \mathrm{H}$, the storage modulus was not restored after the destruction of the network which suggested the lack of restoration capability due to a very slow rate of formation of acylhydrazone bonds at high $\mathrm{pH}$ (Fig. 9c).

\section{Conclusions}

A thermo-responsive self-healable hydrogel was developed via the formation of acylhydrazone bonds between the dialdehyde CNC and hydrazide functionalized POEGMA. AGET ATRP was used to synthesize the POEEGMA-MAA and functionalized with 
the hydrazide groups through hydrazinolysis of MA units. Investigation of thermo-responsive behavior of POEGMA-H revealed a two-step phase transition with increasing temperature due to the coil to globule transition of middle and end blocks of the polymer chains. Rheological measurements showed that the coil to globule transition of copolymer chains at elevated temperatures led to a significant increase in the stiffness of the hydrogel. At low $\mathrm{pH}$, an irregular network with compromised stiffness compared to medium $\mathrm{pH}$ was formed due to the high formation rate of the acylhydrazone bonds. However, at high $\mathrm{pH}$, very slow formation of the acylhydrazone bonds led to a loose network compared to the low and medium pH conditions. The hydrogels possessed a very good selfhealing capability, and they have great potential in biomedical applications.

\section{Conflicts of interest}

There are no conflicts to declare.

\section{Acknowledgements}

KCT acknowledges the support from NSERC. The cellulose nanocrystal was kindly supplied by Celluforce Inc. Authors would also like to thank Ms Samineh Sam for her help in preparing the schematics.

\section{References}

1 O. P. Oommen, S. Wang, M. Kisiel, M. Sloff, J. Hilborn and O. P. Varghese, Adv. Funct. Mater., 2013, 23, 1273-1280.

2 M. C. Cushing and K. S. Anseth, Science, 2007, 316, 1133-1134.

3 Y.-H. Ma, J. Yang, B. Li, Y.-W. Jiang, X. Lu and Z. Chen, Polym. Chem., 2016, 7, 2037-2044.

4 Y.-M. Kim, C.-H. Kim and S.-C. Song, ACS Macro Lett., 2016, 5, 297-300.

5 H. Thérien-Aubin, Y. Wang, K. Nothdurft, E. Prince, S. Cho and E. Kumacheva, Biomacromolecules, 2016, 17, 3244-3251.

6 Y. Li, N. Khuu, A. Gevorkian, S. Sarjinsky, H. Therien-Aubin, Y. Wang, S. Cho and E. Kumacheva, Angew. Chem., Int. Ed., 2017, 56, 6083-6087.

7 Y. Hu, J.-O. You, D. T. Auguste, Z. Suo and J. J. Vlassak, J. Mater. Res., 2012, 27, 152-160.

8 L. Li, J. M. Scheiger and P. A. Levkin, Adv. Mater., 2019, 31, 1807333.

9 X. Hu, Y. Wang, L. Zhang, M. Xu, J. Zhang and W. Dong, Int. J. Biol. Macromolecules, 2018, 108, 558-567.

10 N. M. B. Smeets, E. Bakaic, M. Patenaude and T. Hoare, Acta Biomater., 2014, 10, 4143-4155.

11 I. Urosev, E. Bakaic, R. J. Alsop, M. C. Rheinstädter and T. Hoare, J. Mater. Chem. B, 2016, 4, 6541-6551.

12 J. R. McKee, E. A. Appel, J. Seitsonen, E. Kontturi, O. A. Scherman and O. Ikkala, Adv. Funct. Mater., 2014, 24, 2706-2713.
13 C. Shao, M. Wang, L. Meng, H. Chang, B. Wang, F. Xu, J. Yang and P. Wan, Chem. Mater., 2018, 30, 3110-3121.

14 Y.-J. Liu, W.-T. Cao, M.-G. Ma and P. Wan, ACS Appl. Mater. Interfaces, 2017, 9, 25559-25570.

15 M. Zhu, S. He, Y. Dai, J. Han, L. Gan, J. Liu and M. Long, ACS Sustainable Chem. Eng., 2018, 6, 17087-17098.

16 L. Bai, X. Jiang, Z. Sun, Z. Pei, A. Ma, W. Wang, H. Chen, H. Yang, L. Yang and D. Wei, Cellulose, 2019, 26, 5305-5319.

17 C. Shao, L. Meng, M. Wang, C. Cui, B. Wang, C.-R. Han, F. Xu and J. Yang, ACS Appl. Mater. Interfaces, 2019, 11, 5885-5895.

18 W. Li, S. Lu, M. Zhao, X. Lin, M. Zhang, H. Xiao, K. Liu, L. Huang, L. Chen, X. Ouyang, Y. Ni and H. Wu, Polymers, 2018, 10, 1392.

19 W. Huang, Y. Wang, Z. Huang, X. Wang, L. Chen, Y. Zhang and L. Zhang, ACS Appl. Mater. Interfaces, 2018, 10, 41076-41088.

20 H. Liu, C. Li, B. Wang, X. Sui, L. Wang, X. Yan, H. Xu, L. Zhang, Y. Zhong and Z. Mao, Cellulose, 2018, 25, 559-571.

21 G. Xiao, Y. Wang, H. Zhang, L. Chen and S. Fu, Carbohydr. Polym., 2019, 218, 68-77.

22 R. Chang, X. Wang, X. Li, H. An and J. Qin, ACS Appl. Mater. Interfaces, 2016, 8, 25544-25551.

23 X. Yang, G. Liu, L. Peng, J. Guo, L. Tao, J. Yuan, C. Chang, Y. Wei and L. Zhang, Adv. Funct. Mater., 2017, 27, 1703174.

24 C. Shao, M. Wang, H. Chang, F. Xu and J. Yang, ACS Sustainable Chem. Eng., 2017, 5, 6167-6174.

25 M. Patenaude, N. M. B. Smeets and T. Hoare, Macromol. Rapid Commun., 2014, 35, 598-617.

26 N. Grishkewich, N. Mohammed, J. Tang and K. C. Tam, Curr. Opin. Colloid Interface Sci., 2017, 29, 32-45.

27 E. Lam, K. B. Male, J. H. Chong, A. C. W. Leung and J. H. T. Luong, Trends Biotechnol., 2012, 30, 283-290.

28 R. Nasseri, C. P. Deutschman, L. Han, M. A. Pope and K. C. Tam, Mater. Today Adv., 2020, 5, 100055.

29 B. Peng, N. Grishkewich, Z. Yao, X. Han, H. Liu and K. C. Tam, ACS Macro Lett., 2012, 1, 632-635.

30 E. Bakaic, N. M. B. Smeets and T. Hoare, RSC Adv., 2015, 5, 35469-35486.

31 J.-F. Lutz, Adv. Mater., 2011, 23, 2237-2243.

32 J.-F. Lutz, K. Weichenhan, Ö. Akdemir and A. Hoth, Macromolecules, 2007, 40, 2503-2508.

33 J.-F. Lutz, A. Hoth and K. Schade, Des. Monomers Polym., 2009, 12, 343-353.

34 J.-F. Lutz and A. Hoth, Macromolecules, 2006, 39, 893-896.

35 N. M. B. Smeets, E. Bakaic, M. Patenaude and T. Hoare, Chem. Commun., 2014, 50, 3306-3309.

36 E. Bakaic, N. M. B. Smeets, H. Dorrington and T. Hoare, RSC Adv., 2015, 5, 33364-33376.

37 I. Urosev, H. Dorrington, N. Muzzin, R. Alsop, E. Bakaic, T. Gilbert, M. Rheinstädter and T. Hoare, ACS Appl. Polym. Mater., 2019, 1, 369-380.

38 X. Yang, E. Bakaic, T. Hoare and E. D. Cranston, Biomacromolecules, 2013, 14, 4447-4455.

39 E. Larsson, A. Boujemaoui, E. Malmström and A. Carlmark, RSC Adv., 2015, 5, 77643-77650. 
40 R. Cha, Z. He and Y. Ni, Carbohydr. Polym., 2012, 88, 713-718.

41 J. Tang, M. U. Javaid, C. Pan, G. Yu, R. M. Berry and K. C. Tam, Carbohydr. Polym., 2020, 229, 115486.

42 J. Yang, C.-R. Han, X.-M. Zhang, F. Xu and R.-C. Sun, Macromolecules, 2014, 47, 4077-4086.

43 J. R. McKee, S. Hietala, J. Seitsonen, J. Laine, E. Kontturi and O. Ikkala, ACS Macro Lett., 2014, 3, 266-270.

44 J. Wei, Y. Chen, H. Liu, C. Du, H. Yu and Z. Zhou, Carbohydr. Polym., 2016, 147, 201-207.

45 M. C. B. de Figueirêdo, M. d. F. Rosa, C. M. L. Ugaya, M. d. S. M. d. Souza Filho, A. C. C. d. Silva Braid and L. F. L. d. Melo, J. Cleaner Prod., 2012, 35, 130-139.

46 K. A. Mahmoud, J. A. Mena, K. B. Male, S. Hrapovic, A. Kamen and J. H. T. Luong, ACS Appl. Mater. Interfaces, 2010, 2, 2924-2932.

47 T. Kovacs, V. Naish, B. O’Connor, C. Blaise, F. Gagné, L. Hall, V. Trudeau and P. Martel, Nanotoxicology, 2010, 4, 255-270.

48 E. Gicquel, C. Martin, Q. Gauthier, J. Engström, C. Abbattista, A. Carlmark, E. D. Cranston, B. Jean and J. Bras, Biomacromolecules, 2019, 20, 2545-2556.

49 K. J. De France, K. J. W. Chan, E. D. Cranston and T. Hoare, Biomacromolecules, 2016, 17, 649-660.

50 Z. Guo, W. Ma, H. Gu, Y. Feng, Z. He, Q. Chen, X. Mao, J. Zhang and L. Zheng, Soft Matter, 2017, 13, 7371-7380.

51 A. Dirksen, S. Dirksen, T. M. Hackeng and P. E. Dawson, J. Am. Chem. Soc., 2006, 128, 15602-15603.

52 T. Lu, Q. Li, W. Chen and H. Yu, Compos. Sci. Technol., 2014, 94, 132-138.
53 A. Simula, V. Nikolaou, A. Anastasaki, F. Alsubaie, G. Nurumbetov, P. Wilson, K. Kempe and D. M. Haddleton, Polym. Chem., 2015, 6, 2226-2233.

54 N. M. B. Smeets, M. Patenaude, D. Kinio, F. M. Yavitt, E. Bakaic, F.-C. Yang, M. Rheinstädter and T. Hoare, Polym. Chem., 2014, 5, 6811-6823.

55 N. Grishkewich, S. P. Akhlaghi, Y. Zhaoling, R. Berry and K. C. Tam, Carbohydr. Polym., 2016, 144, 215-222.

56 S.-i. Yamamoto, J. Pietrasik and K. Matyjaszewski, Macromolecules, 2008, 41, 7013-7020.

57 J. A. Jones, N. Novo, K. Flagler, C. D. Pagnucco, S. Carew, C. Cheong, X. Z. Kong, N. A. D. Burke and H. D. H. Stöver, J. Polym. Sci., Part A: Polym. Chem., 2005, 43, 6095-6104.

58 Á. Szabó, I. Szanka, G. Tolnai, G. Szarka and B. Iván, Polymer, 2017, 111, 61-66.

59 Z. L. Yao and K. C. Tam, Polymer, 2012, 53, 3446-3453.

60 Y. Li, Z. Ye, L. Shen, Y. Xu, A. Zhu, P. Wu and Z. An, Macromolecules, 2016, 49, 3038-3048.

61 A. Gharachorlou and F. Goharpey, Macromolecules, 2008, 41, 3276-3283.

62 M. L. Gardel, J. H. Shin, F. C. MacKintosh, L. Mahadevan, P. Matsudaira and D. A. Weitz, Science, 2004, 304, 1301-1305.

63 F. C. MacKintosh, J. Käs and P. A. Janmey, Phys. Rev. Lett., 1995, 75, 4425-4428.

64 P. H. J. Kouwer, M. Koepf, V. A. A. Le Sage, M. Jaspers, A. M. van Buul, Z. H. Eksteen-Akeroyd, T. Woltinge, E. Schwartz, H. J. Kitto, R. Hoogenboom, S. J. Picken, R. J. M. Nolte, E. Mendes and A. E. Rowan, Nature, 2013, 493, 651-655.

65 C. R. Becer, S. Hahn, M. W. M. Fijten, H. M. L. Thijs, R. Hoogenboom and U. S. Schubert, J. Polym. Sci., Part A: Polym. Chem., 2008, 46, 7138-7147. 